\title{
Stimuli responsive membranes in separation processes- short review
}

\author{
Marek BRYJAK ${ }^{1}$, Joanna WOLSKA, Anna SIEKIERKA, Jan KUJAWSKI \\ Department of Polymer and Carbon Materials, Wroclaw University of Technology, \\ 50-370 Wroclaw
}

Keywords: responsive polymers, pore filled membrane, membrane valves

\begin{abstract}
.
The paper discusses some basic issues related to synthesis and properties of stimuli responsive membranes. Two commonly studied forms of these membranes are presented, namely pore surface grafted and pore volume functionalized membranes. The critical feature allowing to classify membrane to one of the above category is their grafting yield. The first kind of membranes, known under the name of 'membrane valves', can be used in stimuli controlled filtration when membrane cut-off is controlled by means of external stimuli. The second category, called sometimes 'gating membranes', can be used for transport facilitation of some species. The paper is illustrated by description of our attempts in syntheses of both membrane forms and evaluation of their separation properties.
\end{abstract}

\section{INTRODUCTION}

Since the previous century, the development of membrane technology has been related to the availability of polymers on the market. Unfortunately, a largescale production of new polymers has not been developed for the last two decades and it is not expected to be launched soon. Such situation has enforced a search for some alternative methods that allow tailoring new kind of membranes. They can be prepared in two ways: (i) by modification of commercial polymer and preparation of membrane from it, or (ii) by manufacturing membrane in accordance to the common procedures and their modification. It is obvious that the second approach is fast, robust and versatile [1].

Today "stimuli-responsive polymers" have gained the growing interest [2]. They have the ability to respond to environmental changes and their responsiveness is applied to membranology where membrane permeability is controlled or triggered by such chemical and/or physical stimuli as: temperature, $\mathrm{pH}$, ionic strength, concentration of some substances, light, magnetic field and so on. The stimuli-responsive membranes, SRM, may find various applications in controlled drug delivery, separation, water treatment, construction of chemical sensor and so on [3]. Wandera et al. published recently an extended review on stimuli responsive membranes [4].

Generally, SRM's can be formed by means of two procedures: from stimuli responsive material (or their blend/mixtures with other polymers) or by modification of existing membranes by stimuli responsive polymers. In this review the second option will be considered mostly. When porous membrane is taken as the substrate there are two options of modification: to functionalize pore-surface or to fill the pore volume by a new polymer [5]. The sketch of both obtained structures is shown in Fig. 1.

\footnotetext{
${ }^{1}$ Corresponding author: (M.Bryjak) marek.bryjak@pwr.wroc.pl
} 
Pore surface functionalization

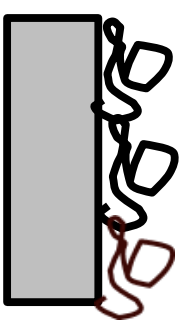

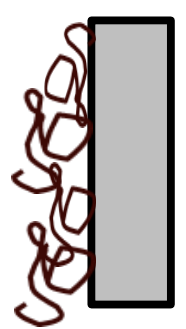

Pore volume filling

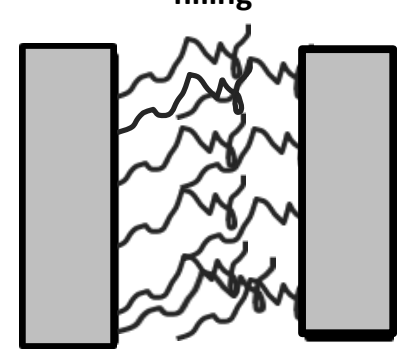

Fig. 1. Porous membranes with pore-surface functionalization and pore-volume filling arrangement

The modification can be made by grafting of stimuli responsive polymers by photo, chemically and/or plasma initiated processes. Depending on the density of grafting, length of grafted polymer, diameter of pores and post-grafting treatment the obtained membranes can show two kinds of properties: they can behave as membrane valve [pore surface functionalized samples] or gating membranes [pore volume filled samples]. Some examples of their character are shown in the following sections of this review. Here, a short presentation of grafting methods and obtained structures of polymer brushes is shown.

Generally, stimuli responsive polymers are grafted according to 'grafting to' or 'grafting from' protocol (Fig 2). The former can be done by physical adsorption of pre-formed polymer chains and their reaction with surface functional groups. The 'grafting from' method is based on starting polymerization of polymers from sites located on the surface. The following methods are used for generation of surface radical: photo-initiation, redox-initiation, plasma initiation or temperature-initiation. More details on these methods can be found in references $[4,6,7]$.
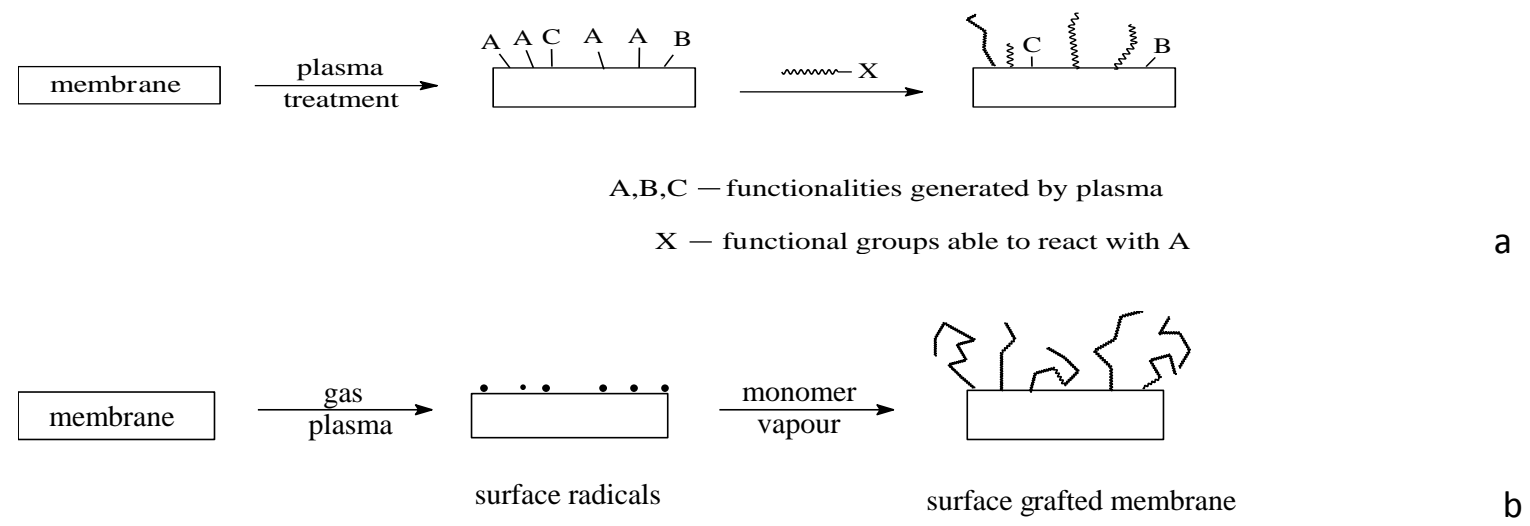

Fig. 2. Grafting to (a) and grafting from (b) mechanisms (adopted from [7])

\section{STIMULI RESPONSIVE MEMBRANE VALVES.}

Yamaguchi et al. [8], as one of the first, described the action of the tunable membranes that can be used for separation of multicomponent mixture [9]. The scheme of the action of membrane valves is illustrated on Fig. 3 


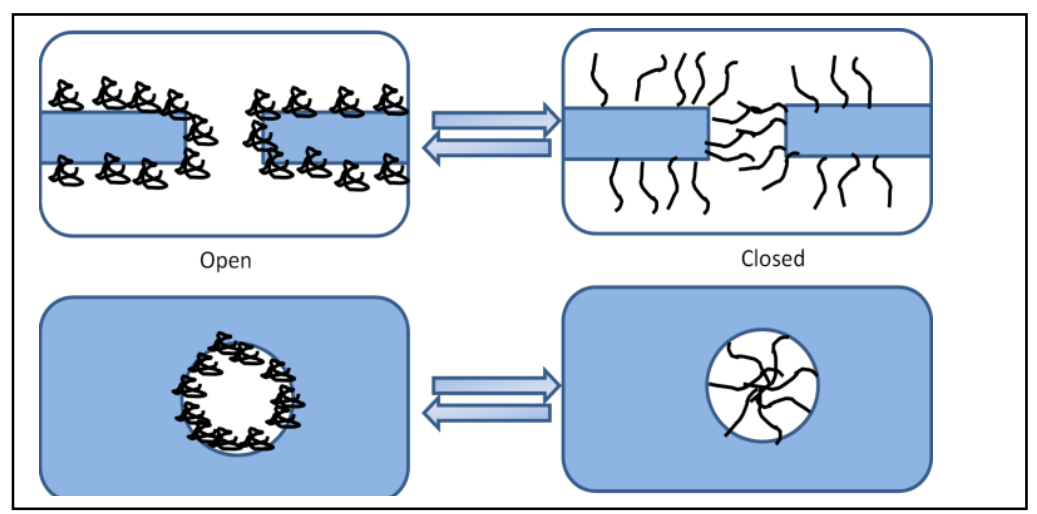

Fig. 3. Stimuli responsive membranes with pores that alter their diameter (adopted from [10])

In the case of use of mono-sensitive response polymers, the valves are tunable to one stimuli. However, when double-sensitive polymers are grafted, the system follows the change of two stimulus. That case is visible for copolymers of poly( $\mathrm{N}$-isopropylacrylaminde), PNIPAM, and poly(acrylic acid), PAA [1, 11]. The first polymer is sensitive to temperature (critical temperature is $32^{\circ} \mathrm{C}$ ) while the second one weakly responds to temperature (critical temperature is $25^{\circ} \mathrm{C}$ ) but strongly to $\mathrm{pH}$ (critical $\mathrm{pH} 4.7$ ). The change of flux with relation to feed acidity and temperature is shown in Fig. 4.

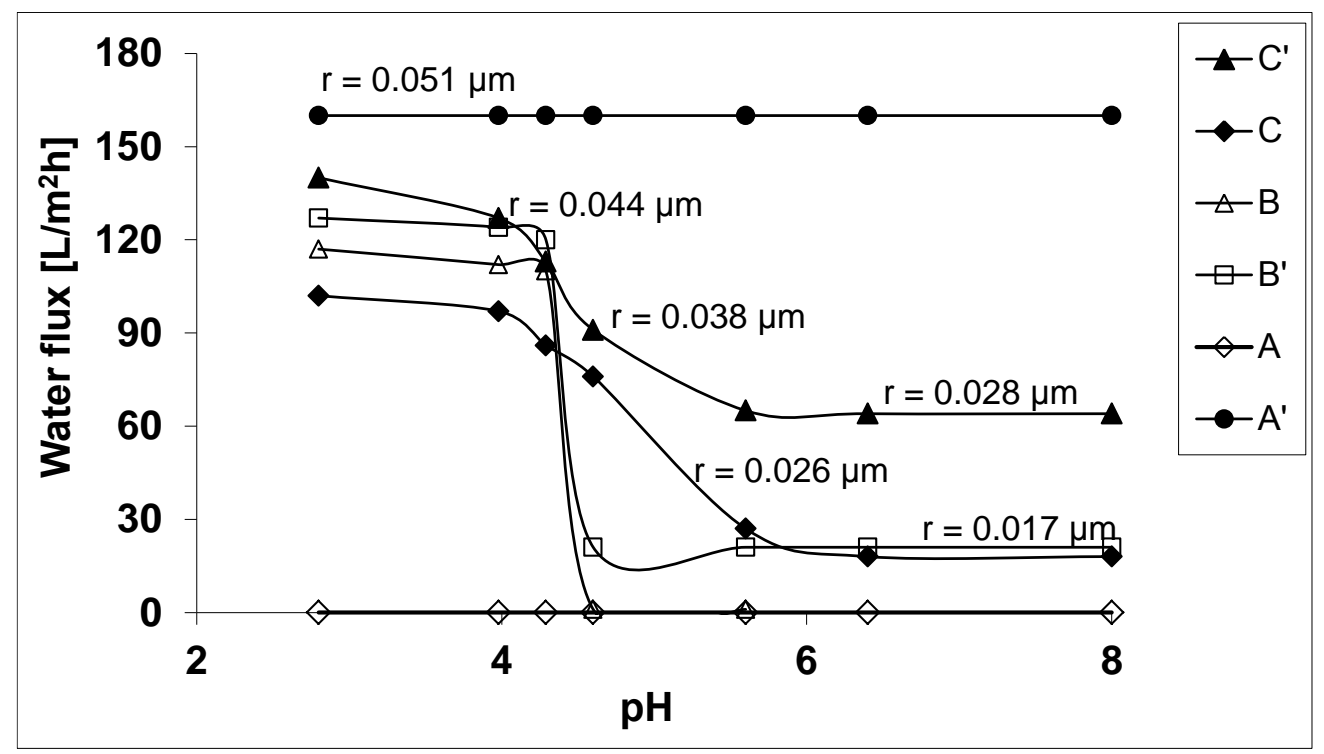

Fig. 4. Permeate flux vs. solution $\mathrm{pH}$ and temperature. Celgard membranes grafted with NIPAM (A $\left.20^{\circ} \mathrm{C}, A^{\prime} 45^{\circ} \mathrm{C}\right), A A\left(B 20^{\circ} \mathrm{C}, B^{\prime} 45^{\circ} \mathrm{C}\right), A A: N I P A M=1: 2\left(C 20^{\circ} \mathrm{C}, C^{\prime} 45^{\circ} \mathrm{C}\right)$ (adopted from [1])

The pore diameter was calculated at $20^{\circ} \mathrm{C}$ and $\mathrm{pH}=2.5$. At the first glance, the data in Fig. 4 show that the prepared membranes are fully tunable and change their properties with relation to $\mathrm{pH}$ and temperature. However, the grafted NIPAM-AA copolymer shows other interesting features. When the modified $\mathrm{RO}$ membrane is kept at $\mathrm{pH}$ above 5, it becomes more permeable to water. When it is fouled with protein, its treatment at $45^{\circ} \mathrm{C}$ is enough to remove the fouling layer [11]. The first effect resulted from surface hydrophilization while the second one by peeling off the layer by expanding PNIPAM molecules. 


\section{STIMULI RESPONSIVE GATES}

Some interesting effects can be observed when pores of membranes are filled with stimuli responsive gels. At the beginning, when pores were filled by polyelectrolytes [12] the membranes served as specific ion-exchange membranes. Later, when stimuli responsive polymers were applied, the membranes got the gating character [13]. The papers of Yamaguchi's team gave the milestones in preparation and characterization of such membranes. Stimuli responsive pore filled membranes were used by Bryjak et al. for separation of lithium ions from aqueous solutions [14-16]. Below some results of these studies are described.

The copolymers of acrylic acid, AA, and di(ethylene glycol)methyl ether methacrylate, DEGMEM, or N-isopropylacylamide, NIPAM, and di(ethylene glycol)methyl ether methacrylate were grafted into pores of Celgard membranes. The stimuli gating membranes were tested in dialysis of $\mathrm{LiCl}, \mathrm{NaCl}$ and $\mathrm{KCl}$ salts. It was found that transport of potassium, sodium and lithium ions by membranes with grafted PNIPAM-coDEGMEM was more efficient than transport through PNIPAM only. The presence of ethylene glycol functionalities improves permeability of membranes in the following order $\mathrm{Li}>\mathrm{Na}>\mathrm{K}$. In the case of $\mathrm{pH}$-sensitive membranes, with PAA or PAA-co-DEGMEM, the transport of investigated salts was related to presence of co-monomer and the degree of ionization of carboxyl groups in the polyacid backbone. It was suggested that these membranes could be used for selective separation of lithium chloride in the $\mathrm{pH}$-controlled processes [14].

The latter membranes were tested for lithium separation [15]. It was found that the best results were obtained for 1:2 copolymer of AA:DEGMEM. The structure of pore-filled membrane is shown in Fig. 5.

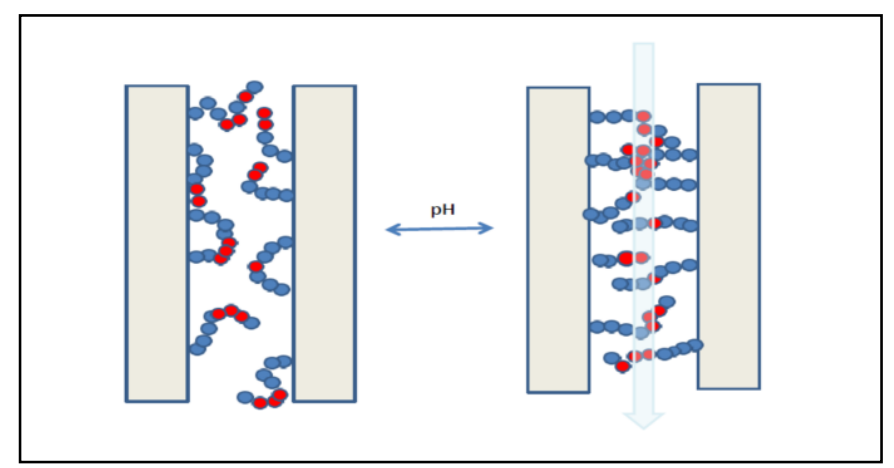

Fig. 5. Gating effect in pore-filled membrane under pH-stimuli (adopted from [15])

It was assumed that due to the $\mathrm{pH}$ induced movements of PAA segments, the ethylene glycol units were able to be arranged into the lithium transporting ducts. These membranes were tested for $\mathrm{LiCl}$ extraction in a capacitive deionization system. The capacitive deionization is based on electrosorption od ions in double layer of porous electrode (the case of supercapacitor). When electrode is wrapped with selective membrane some ions are allowed to pass while transport of others is restricted. The effect of $\mathrm{pH}$ on electorsorption of $\mathrm{LiCl}$ can be seen in Fig. 6 [16]. 


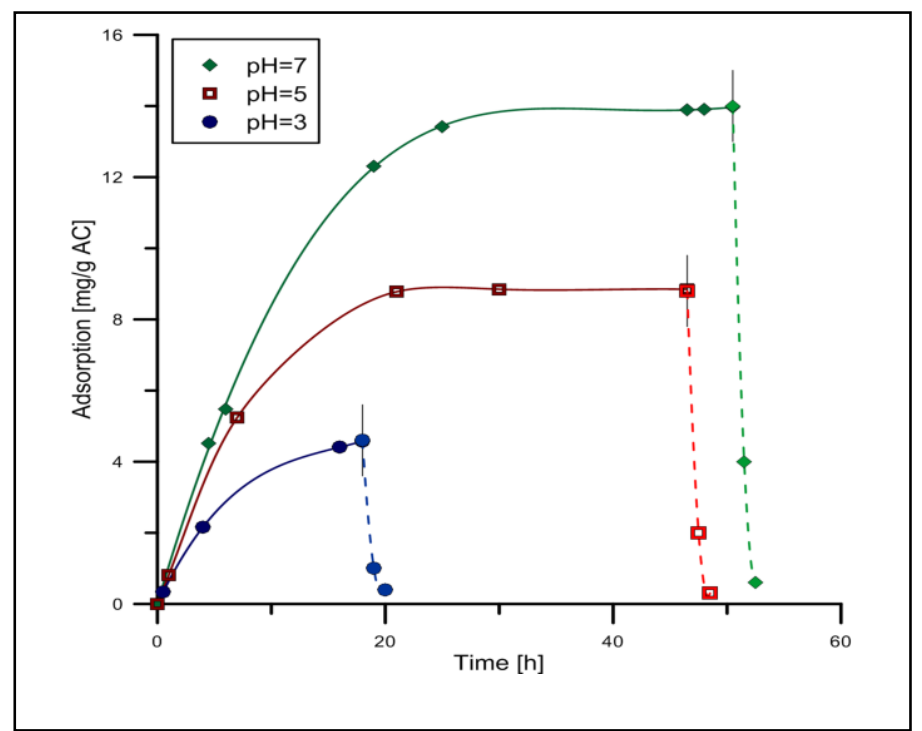

Fig. 6. Effect of pH on lithium sorption (adopted from [16])

It can be seen that presence of poly(acrylic acid) significantly affected transport of $\mathrm{LiCl}$ through membranes at various $\mathrm{pH}$ and that effect was not caused by dissociation of carboxylic groups (Fig. 6).

When acrylic acid is copolymerized with glycidyl methacrylate and the latter one is functionalized with crown-4 ether much more efficient separating membrane could be obtained. The preliminary results on separation of $\mathrm{LiCl}$ and $\mathrm{KCl}$ by means of capacitive system equipped with such membranes is presented in Fig. 7

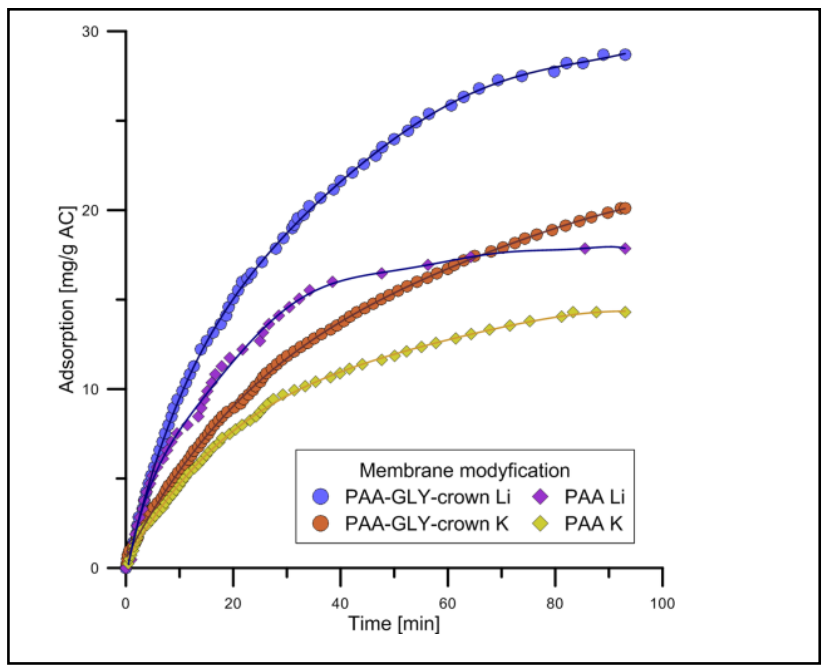

Fig. 7. Effect crown-4 ether on electrosorption of $\mathrm{LiCl}$ and $\mathrm{KCl}$. Process at $\mathrm{pH}=5$

It is evident that presence of crown-4 structures significantly improved lithium permeability. When we consider the molecular weights of $\mathrm{LiCl}$ and $\mathrm{KCl}(42.2 \mathrm{~g} / \mathrm{mol}$ against $74.6 \mathrm{~g} / \mathrm{mol})$ the difference will be much larger. Hence the membranes showed the Li gating effect and could be used in separation of lithium chloride. However, there is one more problem that should be tested - the membrane stability. A series of ten cycles of sorption and desorption has been conducted. For each of it, adsorption of $\mathrm{LiCl}$ was measured. It was found that membranes did not show any deterioration (Fig. 8). 


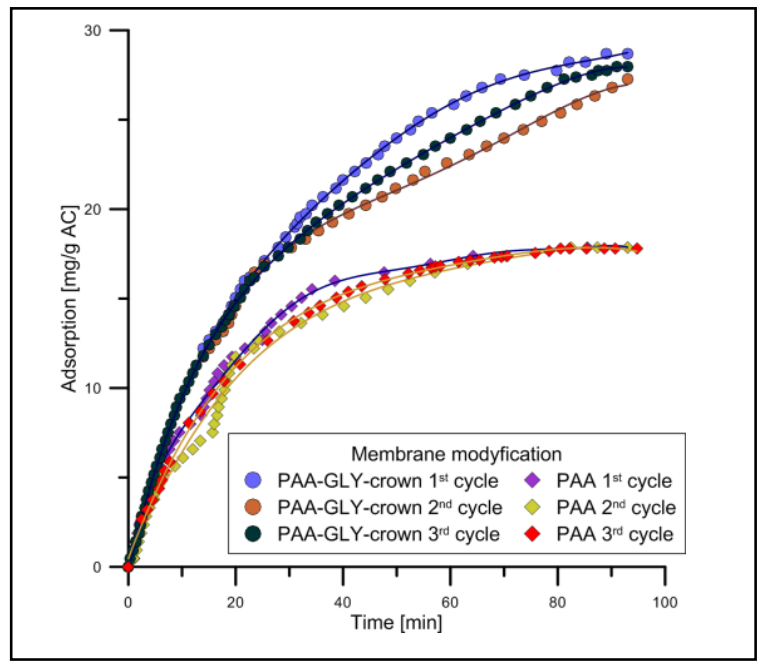

Fig. 8 Cyclic adsorption curves for PAA-GLY-crown (round) and PAA (diamond) membranes. For clarity of the picture three runs were presented only.

It can be concluded that membranes are stable during their operation - crown- 4 ether was covalently connected to the glycidyl units.

\section{CONCLUSIONS}

Stimuli responsive membranes in both their variants (as membrane valves or pore filled membranes) offer new brand of polymer separators that can be used for selective extraction of targeted species. The ability of membranes to adjust to the external conditions allow to develop new separation processes.

\section{Acknowledgement}

The work was supported by Wroclaw Research Centre EIT+ within the project "The Application of Nanotechnology in Advanced Materials" - NanoMat (POIG.01.01.02-02-002/08) co-financed by the European Regional Development Fund (Operational Program of Innovative Economy, 1.1.2.)

\section{LITERATURE}

[1] Wolska J, Smolinska-Kempisty K, Bryjak M, Kujawski W, Polypropylene membranes with the double sensitivity effect, J.Appl.Polym Sci., 132, (2015) 41763-41772

[2] Islam MR, Lu Z, Li X, Sarker AK, Hu L, Choi P, Li X, Hakobyan N, J. Serpe MJ, Responsive polymers for analytical applications: A review, Anal. Chim. Acta 789 (2013) $17-32$

[3] Xie R, Li Y, Chu LY, Preparation of thermo-responsive gating membranes with controllable response temperature, J. Membr. Sci., 289 (2007) 76-85

[4] Wandera D, Wickramasinghe SR, Hussona SM, Stimuli-responsive membranes, J. Membr. Sci., 357 (2010) 6-35

[5] He D, Susanto H, Mathias Ulbricht M, Photo-irradiation for preparation, modification and stimulation of polymeric membranes, Prog. Polym. Sci., 34 (2009) 62-98

[6] Bryjak M, Gancarz I, Smolinska K, Plasma nanostructuring of porous polymer membranes, Adv. Colloid Inter. Sci., 161 (2010) 2-9 
[7] Bryjak M, Gancarz I, Plasma modification of polymer membranes, in Hilal N, Khayet M, Wright CJ, [Eds] Membrane Modification, Technology and Applications, CRC Press, Boca Raton 2o12, ISBN 978-1-4398-6635-1

[8] Choi YJ, Yamaguchi T, Nakao S, A novel separation system using porous thermosensitive membranes, Ind. Eng. Chem. Res. 39 (2000) 2491-2495

[9] Huang R; Kostanski L K; Filipe CDM; Ghosh R.Environment responsive hydrogel based ultrafiltration membranes for protein bioseparation, J. Membr. Sci. 336 (2009) 42-49

[10] Chu L., Xie R, Ju X, Stimuli responsive membranes: smart tools for controllable mass transfer and separation processes, Chin J Chem Engn., 19 (2011) 891-903

[11] Yu S, Liu X, Liu J, Wu D, Liu M, Gao C, Surface modification of thin-film composite polyamide reverse osmosis membranes with thermo-responsive polymer (TRP) for improved fouling resistance and cleaning efficiency, Sep. Pur. Tech., 76 (2011) 283-291

[12] Mika AM, Childs RF, Dickson JM, McCarry BE, Gagnon DR, A new class of polyelectrolyte-filled microfiltration membranes with environmentally controlled porosity, J. Membr. Sci. 108 (1995) 37-46.

[13] Ito T, Sato Y, Yamaguchi T, Nakao S, Response mechanism of a molecular recognition ion gating membrane, Macromolecules 37 (2004) 3407-3414

[14] Smolinska K, Bryjak M, Stimuli response polypropylene membranes as selective separators for alkaline ions, Desalination 300 (2012) 64-69

[15] Smolinska K, Marek Bryjak M, Wolska J, Kujawski W, pH-sensitive membranes for lithium separation, Mater. Chem. Phys., 148 (2014) 548-553

[16] Bryjak M, Siekierka A, Kujawski J, Smolinska-Kempisty K, Kujawski W, Capacitive deionization for selective extraction of lithium from aqueous solutions, J. Membr. Sep. Technol., 4 (2015) 110-115 